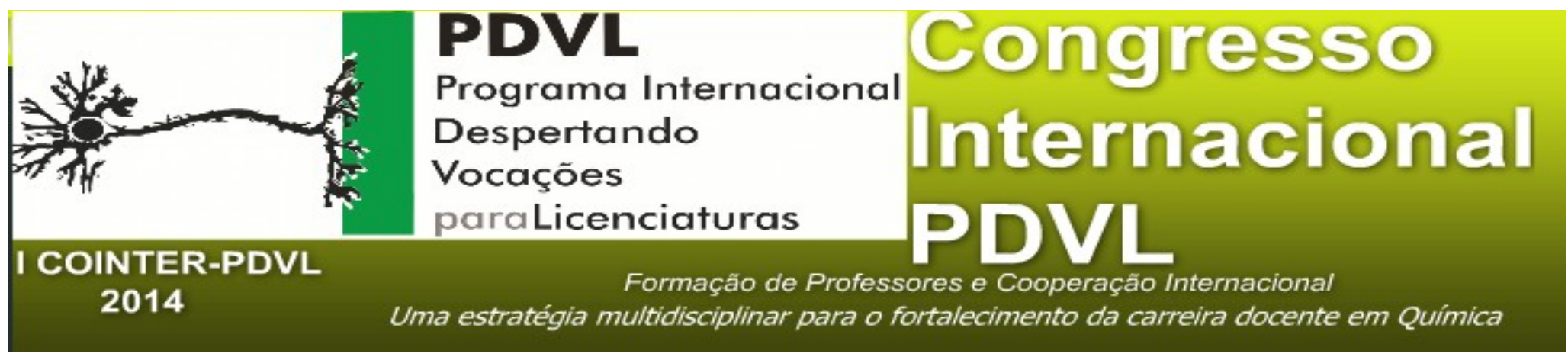

\title{
EDUCAÇÃO AMBIENTAL: UMA NOVA FORMA DE ENSINAR OS CONTEÚDOS DE QUÍMICA, FÍSICA E DESENHO TÉCNICO PARA OS ALUNOS DO ENSINO MÉDIO DO INSTITUTO FEDERAL DA PARAÍBA.
}

Apresentação: Pôster

\author{
M. V. S. Silva ${ }^{1}$; J. S. Silva²; B. N. Jacob ${ }^{3}$; R. X. Silva ${ }^{4}$.
}

${ }^{1}$ Instituto Federal de Educação, Ciência e Tecnologia da Paraíba (IFPB) - Campus João Pessoa, email: marcusvinicius16@hotmail.com.br ${ }^{2}$ IFPB, e-mail: jeffersonsantossilva@hotmail.com.br;

${ }^{3}$ IFPB, e-mail: brunojacob_89@hotmail.com.br; ${ }^{4}$ IFPB, email: xavier.lxrl@gmail.com

\section{Introdução}

Discussões sobre a temática energia, em particular, o consumo desenfreado de recursos energéticos não renováveis tornou-se alvo de grandes discussões da sociedade nos dias atuais. Muitas delas agridem o meio ambiente prejudicando o bem estar da sociedade, e dessa forma, vem modificando gradativamente o comportamento dos indivíduos que fazem parte dela. Diante da problemática, surge a necessidade de se recorrer a meios de energias renováveis que menos agridem e modificam o meio ambiente, como a energia solar usando painéis fotovoltaicos. A mesma se caracteriza como um meio de energia renovável, por causar menos impacto ambiental e usar os raios solares - estes inesgotáveis - para obtenção de energia. De acordo com RUTHER (2004, p.20), o efeito fotovoltaico desses painéis faz com que a energia solar seja convertida em energia elétrica. A versão comercial mais encontrada do painel solar é geralmente constituída por uma junção de células produzidas com um semicondutor como o silício cristalino, que se consolidou devido à grande robustez e confiabilidade. Nesta perspectiva, os integrantes do projeto interdisciplinar coordenado pela professora Márcia de Lourdes do IFPB - Instituto Federal da Paraíba - pretendem junto com os alunos do curso de edificações, abordar os conceitos que envolvem as disciplinas de desenho, física, matemática e química no esquema de funcionamento de um painel solar, mediante a construção de uma maquete que o represente satisfatoriamente. De 
acordo com os Parâmetros Curriculares Nacionais (PCN+, 2002, p.135), o ensino por meio de projetos pode ajudar na consolidação da aprendizagem, e propiciar o desenvolvimento do espirito do trabalho em grupo. Portanto, o trabalho realizado no projeto se torna tão importante quanto os exercícios individuais realizados em sala.

\section{Fundamentação Teórica}

Para a ANEEL, agencia responsável por regular o setor, o Brasil, em particular, a região nordeste do país, possui um grande potencial para uso desse recurso já que a maior parte do território está localizada próxima a linha do equador, o que contribui para as condições climáticas favoráveis para uso dessa tecnologia. A figura 1, apresenta a média anual de insolação diária, segundo o Atlas Solarimétrico do Brasil (2000).

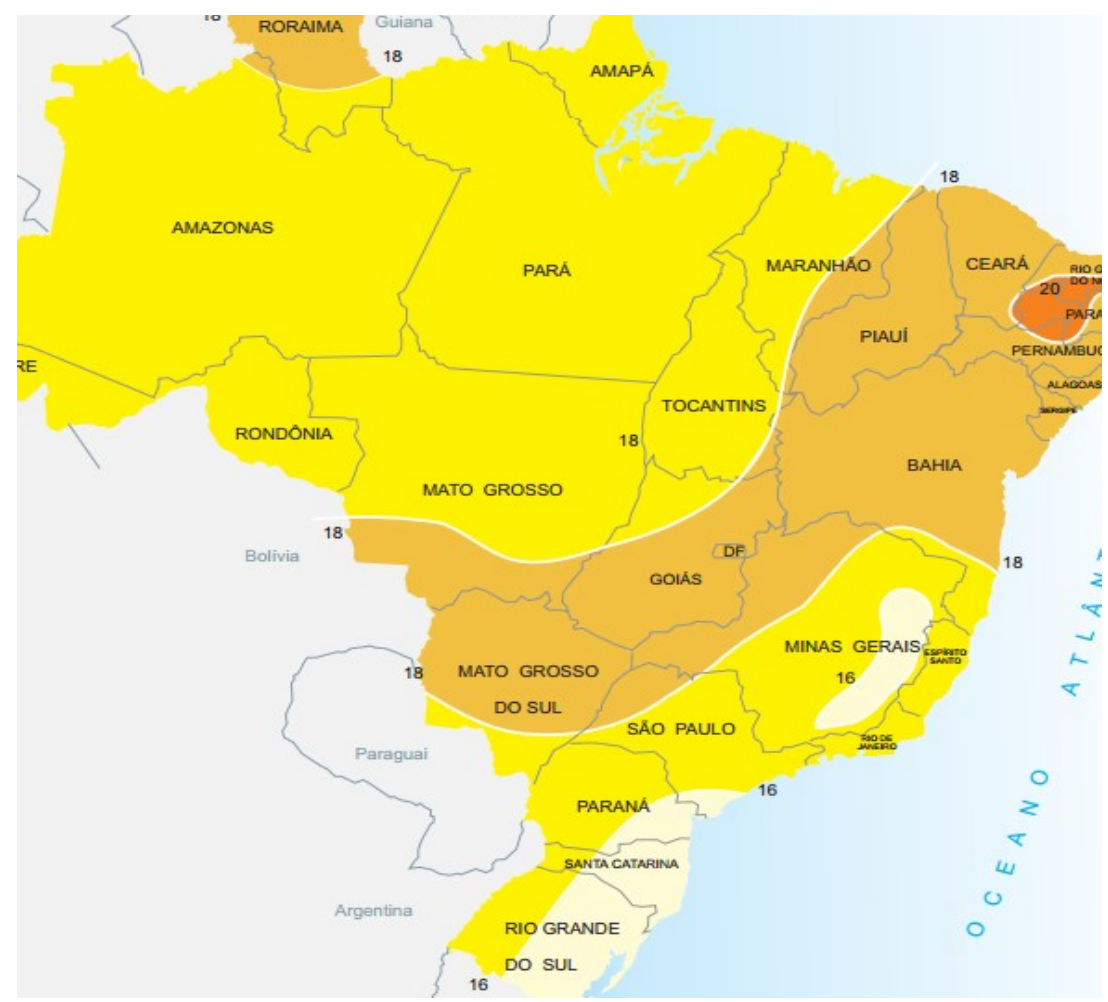

Figura 1 - Radiação solar global diária - média anual (MJ/m.dia). Fonte: CRESEB, atlas solarimétrico do Brasil: banco de dados, 2000. (adaptado).

De acordo com MATTOZO et al. (2004, p.101), fica evidente a necessidade de se aderir a novas alternativas, e que governos trabalhem em prol de tecnologias renováveis. Neste sentido, existe uma grande expectativa de que nos próximos anos haverá uma oferta energética incapaz de suprir uma demanda que não para de crescer, uma vez que, existe um crescimento exponencial do uso de novos equipamentos elétricos, conforme MARCHAIS (2011, p.8) destaca abaixo. 
Seria difícil para a maioria imaginar uma vida sem eletricidade, o que não significa que o consumo seja impossível de controlar com a finalidade de alcançar a Eficiência Energética Ativa. Na verdade, sem a firme resolução de implementar medidas de Eficiência Energética Ativa, os governos deverão agir através da legislação para ter alguma chance de atingir os objetivos e metas de Kyoto. (MARCHAIS, 2011, p.8)

\section{Metodologia}

\section{A sondagem}

Escolher conteúdos de ensino de maneira conjunta contribui para uma melhor aceitação da turma, dessa forma, pode-se comprovar que o processo de aprendizagem acontece de maneira eficaz quando o professor não se depara diante de barreiras que dificultam ao ministrar conceitos abstratos de química e física. Para BIZELLI et al. (2010), as dificuldades encontradas pelos alunos em assimilar certos conteúdos que referem-se ao estudo da ciência microscópica, podem levar muitos deles ao desinteresse e gerar bloqueios que gerem aversão a certos conteúdos, levando em consideração que existem níveis de conhecimento a respeito de determinadas ciências de modo desigual dentro da própria sala, criando grupos em que alguns tem um nível alto de conhecimento, e outro em que os componentes encontram-se desmotivados, portanto, esta queda na qualidade de ensino estimula muitos a recorrer de artifícios que não colaboram para seu crescimento intelectual, como a chamada “decoreba”. Decidimos levar para sala de aula uma abordagem mais dinâmica de como trabalharíamos com o tema, através de um debate, em que decidiríamos junto com a turma, que tipo de captação de energia seria empregada na construção de nossa maquete, e que nos deixaria em condições de saber o que os alunos conheciam a respeito do tema. Esse debate, nos possibilitou traçar as estratégias e separar os conteúdos que nos auxiliariam durante a montagem da maquete.

Abordagem dos conteúdos pertinentes

Ensinar a partir de conhecimentos que levariam os alunos a construção da maquete, tornou a tarefa mais dinâmica e trouxe o aluno para o centro da aprendizagem, pois aumentaram-se as indagações e cada etapa do processo permitiu que os professores abordassem um campo de estudo específico. Sendo assim, cada parte do processo de montagem contou com um tipo de esclarecimento que abordou tanto os conhecimentos do mundo microscópico, quando macroscópico, sempre ressaltando e destacando imprescindivelmente a importância de se adotar métodos alternativos que não modificam o equilíbrio ambiental. Durante as aulas de química e 
física, foram descritos os processos de captação de energia pelo painel solar que deveriam ascender uma determinada quantidade de lâmpadas instaladas no interior da casa, que para elaboração desta última, os alunos contaram com aulas de desenho técnico para determinar as dimensões que melhor aproveitariam a quantidade de luz emitidas pelas lâmpadas, conforme a figura 2. Para PINHEIRO E MENDES (2007), este tipo de abordagem faz com que não apareceram melindres durante as aulas que travam a evolução das aulas, resultando num ambiente de cooperação, mesmo sabendo que na maioria das vezes o tempo de estudo na sala de aula é curto e a assimilação dos conteúdos é diferente para cada aluno.

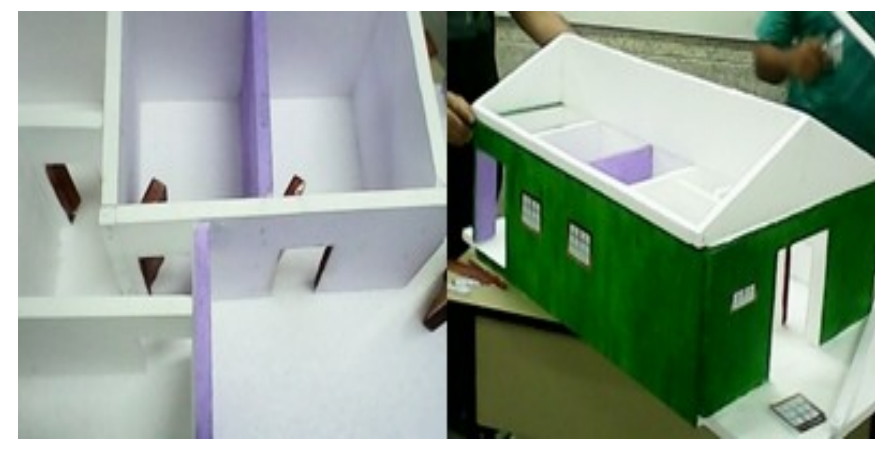

Figura 2 - Montagem da maquete durante as aulas de desenho técnico

\section{Resultados e Discussões}

Elaborar atividades, e dispor de recursos metodológicos que favoreceram a execução desta atividade, certamente foi motivador dentro da sala de aula não só para os alunos, mas também para os professores de outras disciplinas, já que passaram a observar um maior envolvimento dos alunos nas demais áreas, demonstrando uma capacidade de aumentar a assiduidade e participação deles dentro de sala de aula. Neste caminho MORAES e VARELA (2007), afirma que a atividade motivadora traz consigo um poder de identificação que envolve todos os alunos, uma vez, que a atividade escolar deixa de ser vista como uma obrigação, e passa a ser vista como algo prazeroso que habilitaria o professor a desenvolver outras habilidades que são especificas para cada indivíduo.

Segundo BZUNECK (2000), estas habilidades fazem parte do campo da individualidade, portanto, durante cada etapa de elaboração da maquete aconteceu o despertar de uma motivação que é inerente e particular a cada destes alunos, seja por fatores emocionais ou da necessidade de se trabalhar alguma habilidade especificamente. Assim sendo, admite-se que todos os participantes deste projeto interdisciplinar aprenderam na medida em que, foram agentes ativos desse processo de ensino-aprendizagem que tornou o momento dentro de sala de aula receptivo, que criou um âmbito 
de cooperação em que os professores sentiram-se motivados a trabalhar.

\section{Conclusões}

Considerando que o projeto foi realizado com alunos do $1^{\circ}$ ano do ensino médio, onde geralmente se exige um maior cuidado na abordagem devido a uma considerada fase considerada normal de transformações que estes adolescentes passam, e por se tratar de uma classe em que teve contato com outros estudantes que estão pondo em prática pela primeira vez o exercício docente, e que por isso, não contam com a bagagem de outros professores mais experientes, concluímos que a proposta oferecida obteve êxito, uma vez que, a classe se mostrou totalmente receptiva a esse novo método de ensino que contribuiu para a sua formação elucidando conteúdos de maneira dinâmica, ou seja, saindo dos meios tradicionais de se dar aula. Para os alunos do curso de Licenciatura em Química do Instituto Federal da Paraíba (IFPB) o projeto também foi de grande valia, pois estes puderam vivenciar a prática docente, que certamente contribuiu para sua própria formação profissional.

\section{Referências}

RUTHER, R.; Edifícios solares fotovoltaicos, o potencial de geração solar fotovoltaica integrada a edificações urbanas e interligada à rede elétrica publica no brasil. 1, Ed. Florianópolis: UFSC/LABSOLAR, p.11-20, 2004.

PARÂMETROS CURRICULARES NACIONAIS. PCN +, Ensino Médio: Orientações Educacionais complementares aos Parâmetros Curriculares Nacionais. Brasília, 2002.

BIZELLI, H. M. et al. Conteúdos digitais para o ensino de cálculo: aceitação, demandas e expectativas dos alunos. Eixo 10: Tecnologias de Informação e Comunicação-TIC no Processo de Ensinar e Aprender e na Formação Docente. Julho 2010

PINHEIRO, Margarida e MENDES, Antônio José. Contribuições para a construção de um curso EAD para adultos. In: V Conferência Internacional de TIC na Educação. Disponível em: < http://www.inf.ufes.br/ cvnascimento/artigos/dlfile.pdf> Acesso em: maio de 2014.

MORAES, C. R.; VARELA, S. Motivação do aluno durante o processo de ensinoaprendizagem. Revista eletrônica de eduçção, Ano I, N ${ }^{0}$ 01, ago/dez 2007. Disponível em: http://web.unifil.br/docs/revista_eletronica/educacao/Artigo_06.pdf . Acesso em: maio 2014.

BZUNECK, J. A. As crenças de auto-eficácia dos professores. In: F.F. Sisto, G. de Oliveira, \& L. D. T. Fini (Orgs.). Leituras de psicologia para formação de professores. Petrópolis, Rio de Janeiro: Vozes, 2000.

MATTOZO, V.; CAMARGO, C.; LAGE, N. Jornalismo científico aplicado à área de energia no contexto do desenvolvimento sustentável. Brasília, v. 33, 
n. 1, p. 101-107, jan./abril 2004.

CENTRO DE REFERÊNCIA PARA ENERGIA SOLAR E EÓLICA, SERGIO DE SALVO E BRITO - CRESEB. Atlas solimétrico do Brasil, banco de dados terrestre. Disponível em: http://www.cresesb.cepel.br/publicacoes/download/Atlas_Solarimetrico_do_Brasi I_2000.pdf Acesso em: 30 set. 2013.

MARCHAIS, J.; Economias permanentes mediante Eficiência Energética Ativa. São Paulo, Schneider Eletric, 2011. 